Кірпічніков Ю. А., к.т.н.;

Андрощук О. В.;

Петрушен М. В.;

Васюхно C. I.

Центр воєнно-стратегічних досліджень Національного університету оборони України імені Івана Черняховського, Київ

\title{
Теоретичні підходи до побудови архітектури інформаційної системи управління оборонними ресурсами на основі сервісно-оріснтованої моделі
}

Резюме. Стаття присвячена проблемі побудови архітектури інформаційної системи управління оборонними ресурсами, створення якої на сьогодні є одним із пріоритетних завдань оборонної реформи. Децентралізована архітектура та розрізненість існуючих інформаційних систем у галузі управління оборонними ресурсами не дає змоги отримати цілісну картину для прийняття управлінських рішень. Використання архітектури на основі сервісно-орієнтованої моделі дасть змогу інтегрувати процеси управління у єдину інформаційну систему. 3 метою визначення необхідних змін в архітектурі запропоновано теоретико-множинне представлення процесів управління оборонними ресурсами та проведено їх декомпозицію у вигляді функціональних моделей “Як є” і “Як має бути”.

Ключові слова: архітектура інформаційної системи; сервісно-орієнтована модель; процеси управління оборонними ресурсами.

Постановка проблеми. Створення перспективної моделі Збройних Сил (ЗС) України потребує всебічного обгрунтованого підходу до вдосконалення як системи управління військами, так i системи управління оборонними ресурсами, обриси якої визначаються принципами поєднання оперативного i адміністративного керівництва. Водночас, такі чинники, як динамічні зміни у воєнній справі, зростання обсягів і різноплановості завдань, набуття вирішального значення фактора часу в управлінні військами, постійне вдосконалення системи управління оборонними ресурсами та стрімкий розвиток новітніх інформаційних технологій потребують нових підходів до побудови єдиної автоматизованої системи управління ЗС України (САСУ ЗС України).

Ступінь розробленості проблеми. Створення ефективної системи управління 3С України $\epsilon$ одним із пріоритетних завдань оборонної реформи, що спрямоване на реалізацію до кінця 2020 року заходів Матриці досягнення стратегічних цілей i виконання основних завдань Стратегічного оборонного бюлетеня України (у межах оперативної цілі 1.4, стратегічної цілі 1) щодо створення базових основ САСУ ЗС України:

1) системи оперативного (бойового) управління, зв'язку, розвідки та спостереження ЗС України;
2) єдиної інформаційної управління оборонними ресурсами.

Створенню першої компоненти присвячено багато праць вітчизняних вчених $[1,2]$. Основа концепція іiі створення відповідає прийнятій у НАТО концепції C4ISR - cucmеми управління військами "Command, Control, Communications, Computers, Intelligence, Surveillance and Reconnaissance, що у перекладі означає - “управління, контроль, зв'язок, збір і комп'ютерна обробка інформації, спостереження та розвідка" [3].

Під управлінням оборонними ресурсами розуміють специфічну форму адміністративногосподарської діяльності ЗС України, а саме підтримку процесів оборонного та мобілізаційного планування, матеріально-технічного, медичного та інших видів забезпечення, управління фінансовоекономічною діяльністю, особовим складом, організаційною структурою, майном, закупівлями, іншими видами адміністративної діяльності. Ця компонента отримала назву DRMIS - "Defense Resources Management Information System”, що у перекладі означає - “інформаційна система управління оборонними ресурсами”.

Враховуючи складність та масштабність завдань щодо створення та впровадження складових C4ISR та DRMIS, пропонується здійснювати цей процес iз поступовим вирішенням питань щодо удосконалення, нарощування складу й функціональних 
можливостей існуючих, а також розроблення та впровадження нових складових, в межах створення перспективної ЄАСУ ЗС України. Теоретичні підходи щодо створення інформаційної системи управління оборонними ресурсами DRMIS та забезпечення iї взаємодії 3 системою C4ISR $\epsilon$ актуальною темою дослідження.

Метою статті є визначення архітектури інформаційної системи управління оборонними ресурсами на основі аналізу взаємодії функціональних процесів.

Виклад основного матеріалу. Набір функцій ЄАСУ ЗС України планується будувати на базі моделі NATO C3 Classification Taxonomy [4]. Сервісно-оріснтована модель С3 Taxоnоmу подається через ієрархію спроможностей або, так званих, сервісів, що забезпечують компоненти інформаційної інфраструктури (рис. 1).

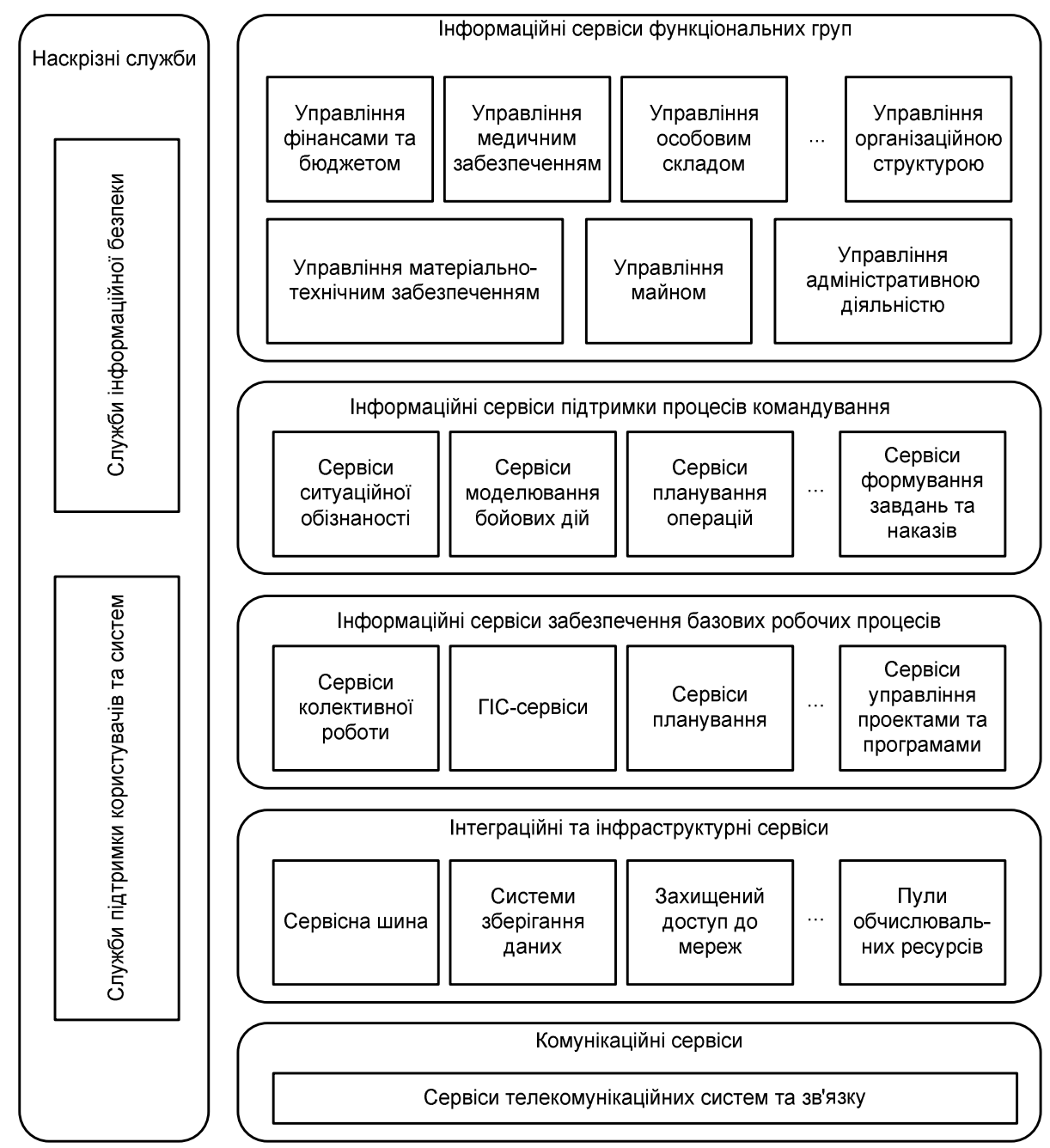

Рис. 1. Загальна карта сервісів на основі сервісно-оріснтованої моделі СЗ Тахопоту сервісів

На верхньому рівні виділено три групи

1. Сервіси

функціональних

груп

(Community of Interest Services, COI) або

"предметні" сервіси - безпосереднього управління різними видами діяльності 3С України (управління озброєнням, логістикою, медичним забезпеченням, фінансами, кадрами тощо);

2. Інформаційні сервіси, що забезпечують базову функціональність (наприклад, ситуаційну обізнаність, моделювання бойових дій, планування операцій, формування завдань та наказів).

3. Базові сервіси (Core Services) інформаційні сервіси, що забезпечують надання базових інформаційних послуг (наприклад, геопросторові дані, внутрішні та зовнішні портали, електронна пошта, управління проектами та програмами).

На нижньому рівні знаходяться:

1. Інтеграційні та інфраструктурні сервіси для всіх інших сервісів вищого рівня ієрархії (наприклад, тактична сервісна шина, системи зберігання даних, захищений доступ до мереж, пули обчислювальних ресурсів та ін.);

2. Комунікаційні сервіси (Communication Services) - сервіси, що формують корпоративну комунікаційну мережу за допомогою комунікаційного обладнання. 
Наскрізними сервісами на кожному рівні $\epsilon$ служби інформаційної безпеки та служби підтримки користувачів та систем.

За результатами попереднього аналізу, розуміння необхідності об'єднання усіх існуючих інформаційних систем ЗС України в цілісну взаємозв'язану інформаційну інфраструктуру призвело до прийняття рішення про створення автоматизованої системи оперативного (бойового) управління C4ISR та інформаційної системи управління оборонними ресурсами DRMIS. На цьому етапі створення систем C4ISR та DRMIS питання їх взаємодії залежать від вирішення питань інтеграції інформації всередині цих систем. У рамках цієї роботи розглядаються підходи до інтеграції інформаційних систем в межах DRMIS.

DRMIS повинна стати центральною ланкою, навколо якої будуть об'єднані інформаційні системи управління оборонними ресурсами, що вже експлуатуються, і що будуть розроблятися в подальшому.

Визначення архітектури DRMIS проведемо на основі розроблення функціональної моделі інтеграції існуючих у ЗС України та перспективних інформаційних систем управління оборонними ресурсами.

Функціональна модель інтеграції розробляється у двох видах:

1) модель "Як $\epsilon ”$ (“As-Is”) - відображає існуючі функціональні процеси;

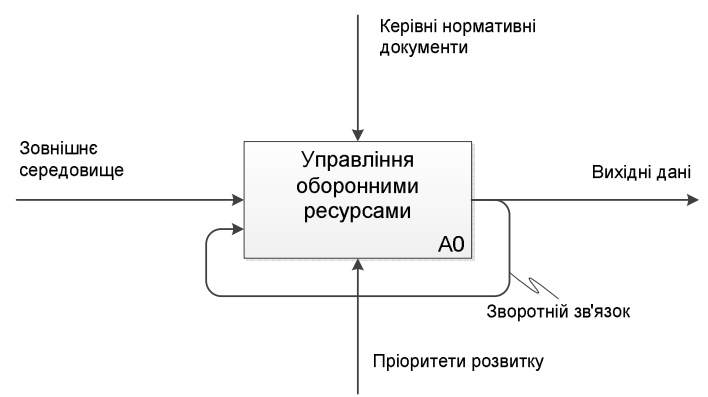

a)
2) модель “Як має бути” (“То-Ве”) відображає необхідні зміни функціональних процесів.

Аналізуючи інформаційні потоки, що виникають при управлінні оборонними ресурсами, необхідно відзначити, що вхідними даними $\epsilon$ інформація про ресурси, регламентуючі керівні документи, пріоритети розвитку ЗС України тощо. Детальний розгляд цієї інформації дає змогу представити процес управління оборонними ресурсами у вигляді:

$$
U=(X, S, Y, \varphi, \psi),
$$

де $X=\left\{x_{1}, x_{2}, \ldots, x_{n}\right\}$ - множина вихідних даних про зовнішне середовище; $S=\left\{s_{1}, s_{2}, \ldots, s_{m}\right\}-$ множина керівних документів, що регламентують процеси управління оборонними ресурсами; $Y=$ $\left\{y_{1}, y_{2}, \ldots, y_{k}\right\}$ - множина даних на виході процесу управління оборонними ресурсами; $\varphi-$ функція, в результаті якої відбувається формування даних на виході; $\psi$ - функція, що формує зворотній зв'язок у системі управління.

Вираз (1) у графічному вигляді можна представити відповідно до методології структурного аналізу SADT (Structured Analysis and Design Technique) за допомогою нотації функціонального моделювання IDEF0 (Integration Definition for Function Modeling) [5], як модель “чорної скриньки" (рис. 2 а), де на входи чиниться зовнішній вплив, а вихідні дані $\epsilon$ результатом управління оборонними ресурсами.

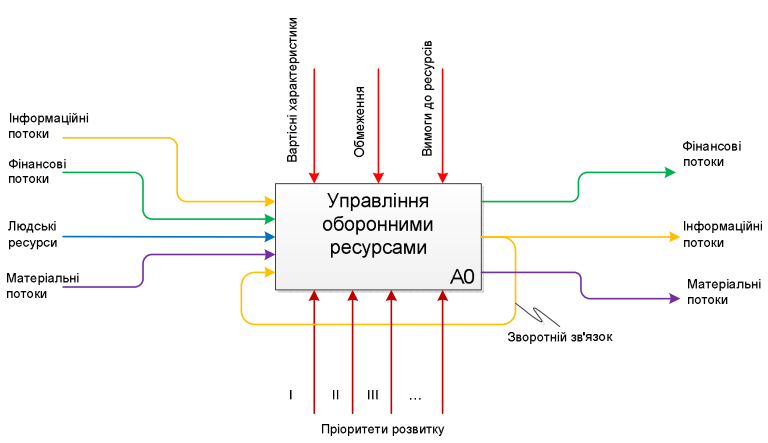

б)

Рис. 2. Функціональна модель управління оборонними ресурсами: а) модель “чорної скриньки”; б) модель “білої скриньки”

Тут елементами множини $X €$ : $x_{1}-$ інформаційні потоки про стан та ретроспективну інформацію про оборонні ресурси, географічні місця їх знаходження і час, коли ці ресурси можуть бути доступні тощо; $x_{2}-$ інформація про наявні людські ресурси; $x_{3}-$ інформація про матеріальні потоки, $x_{4}-$ інформація про фінансові потоки.

Множину $S$ формують керівні нормативні документи, а також пріоритети розвитку 3С України: $s_{1}$ - вимоги до необхідних ресурсів; $s_{2}-$ параметри щодо обмежень та припущень; $s_{3}-$ вартісні характеристики, $s_{n}$ - пріоритети розвитку.

Таким чином, реалізується функція:

$$
\psi: X \times S \rightarrow S, \forall(x, s) \in X \times S,
$$

тобто множина $S$ може змінюватися при надходженні нової інформації (зворотній зв' язок).

Елементами множини $Y €: y_{1}-$ інформаційні потоки про вимоги до ресурсів; $y_{2}-$ фінансові потоки щодо оплати ресурсів; $y_{3}$ - дані о матеріальних потоках тощо.

У результаті формується функція:

$$
\varphi: X \times S \rightarrow Y, \forall(x, s) \in X \times S,
$$


де множина $X$, проходячи функціональні залежності, трансформується в множину $Y$.

На підставі розкриття елементів множин $X$, $S, Y$ формуємо модель “білої скриньки” (рис. 2 б).
Для подальшої декомпозиції процесу управління оборонними ресурсами, визначимо функціональні напрями, проходячи через які, формується множина $Y$ (рис. 3 ).

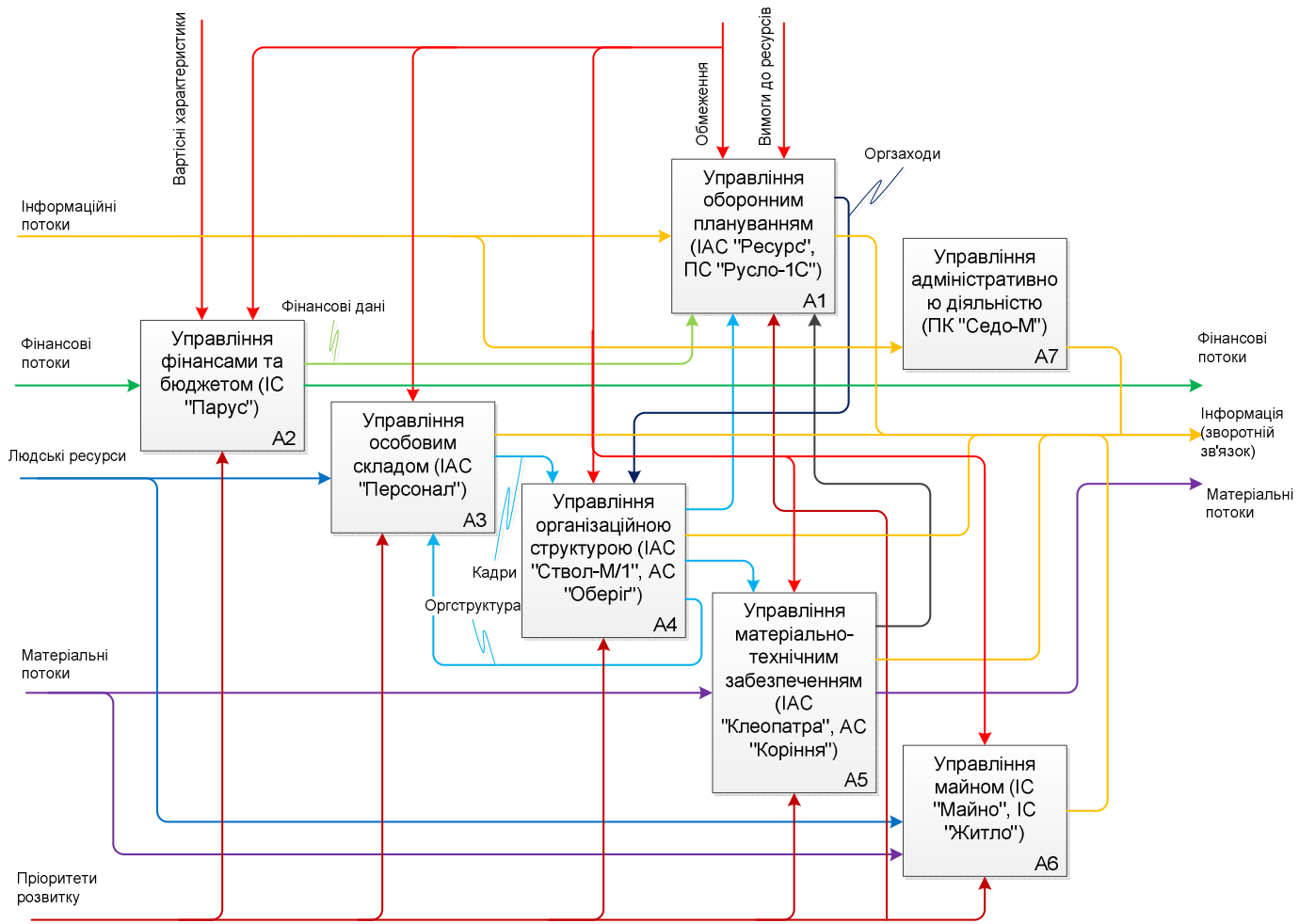

Рис. 3. Функціональна модель інтеграції процесів управління оборонними ресурсами (“Як є”)

Отримана функціональна модель демонструє, що інтеграція процесів управління оборонними ресурсами за існуючою схемою практично відсутня. Обмін обмеженою кількістю даних ведеться тільки між декількома системами. Цілісної картини щодо управління оборонними ресурсами на виході немає.

Як було визначено вище, перспективну функціональну модель інтеграції процесів управління оборонними ресурсами описуємо на основі математичних виразів (1-3). У результаті декомпозиції процесу управління оборонними ресурсами, розроблену модель у графічній нотації IDEF0 представлено на рис. 4.

Отримана функціональна модель дасть змогу забезпечити інтеграцію процесів управління оборонними ресурсами у єдину систему DRMIS. Основою забезпечення інтеграції є інтеграційна платформа із сервісною інтеграційною шиною даних.

Висновки. Основними напрямами створення DRMIS $€$ формування сучасної інформаційної інфраструктури, модернізація та захист інформаційно-телекомунікаційних мереж, забезпечення інтеграції інформаційних систем управління оборонними ресурсами у єдину систему, а також досягнення ii сумісності 3 перспективною системою C4ISR відповідно до стандартів і рекомендацій НАТО.

3 метою визначення архітектури DRMIS y роботі розроблено функціональні моделі процесів управління оборонними ресурсами: модель “Як $\epsilon$ " - відображає існуючі функціональні процеси; модель "Як має бути" - відображає необхідні зміни функціональних процесів.

Основою моделі "Як має бути" $\epsilon$ використання інтеграційної платформи, що забезпечує агрегацію інформації для отримання цілісної картини щодо управління оборонними ресурсами. Розроблені моделі можуть бути використані для управління проектом створення DRMIS. 


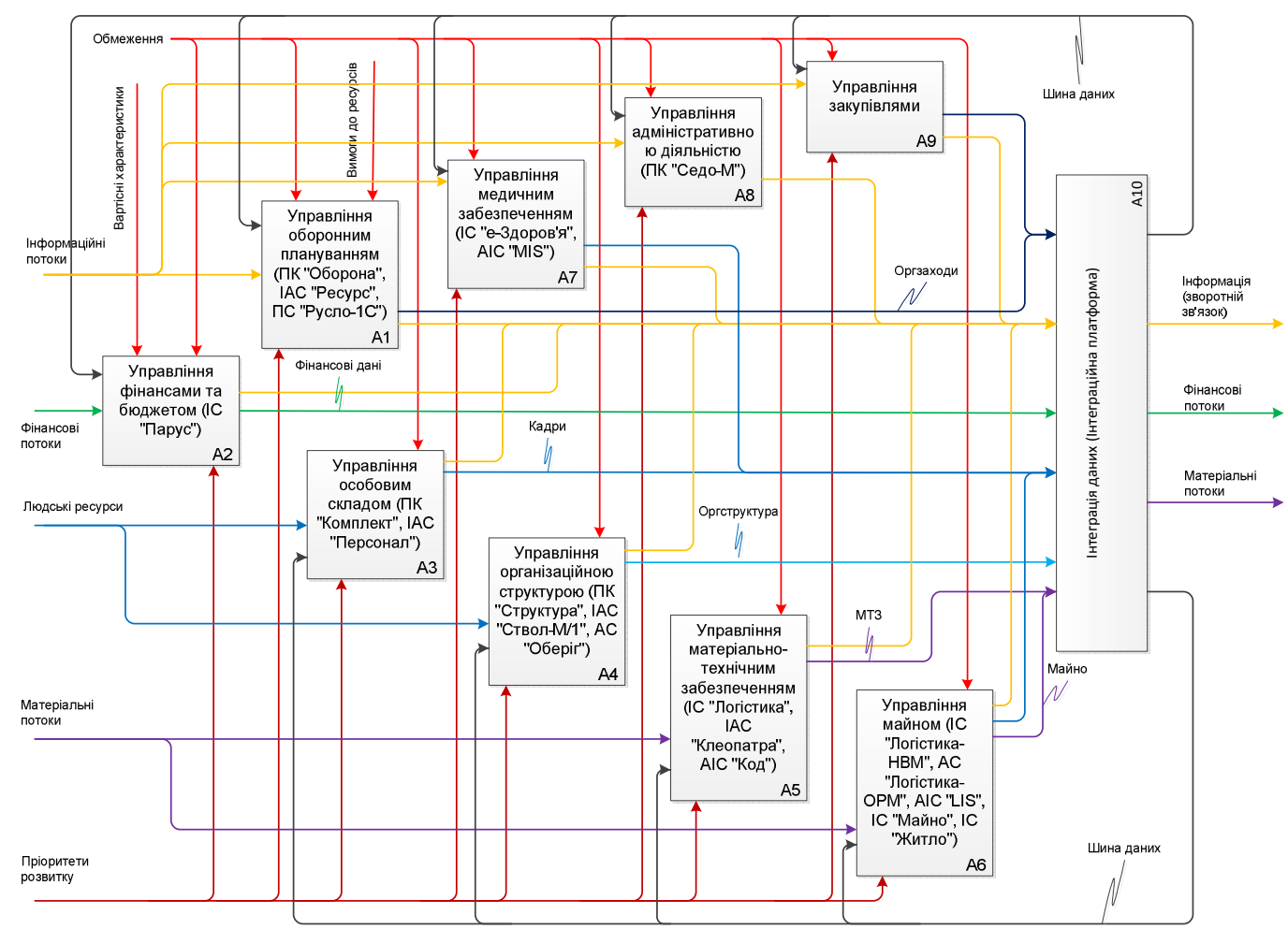

Рис. 4. Функціональна модель інтеграції процесів управління оборонними ресурсами (“Як має бути”)

\section{СПИСОК ВИКОРИСТАНОЇ ЛІТЕРАТУРИ}

1. Морозов А. О. Управління розробкою Єдиної АСУ збройних сил / А. О. Морозов, В. А. Косс // Наука і оборона. - 2006. - № 2. - С. 30-34. Режим доступу: http://www.immsp.kiev.ua/ perspages/koss_va/publ/5_syst_proekt.pdf.

2. Артюх В. М. Современный этап разработки и строительства Единой автоматизированной системы управления Вооруженными Силами Украины / В. М. Артюх, В. К. Медведев // Оборонный вестник. - 2012. - № 1. - С. 15-24. Режим доступу: http://defpol.org.ua/site/files/ OV_1_2012_rus.pdf.
3. C4ISR Architecture Framework Version 2.0 [Electronic Resource] // C4ISR Architecture Working Group U.S. Department of Defense. - 1997. - Mode of access: http://www.afcea.org/education/courses/archfwk2.pdf. 4. NATO C3 Classification Taxonomy [Electronic Resource].- Mode of access: https://www.yumpu.com/ en/document/view/24003661/c3-classificationtaxonomy-nci-agency-nato.

5. INTEGRATION DEFINITION FOR FUNCTION MODELING (IDEF0). Draft Federal Information Processing Standards Publication 183 ,1993 December 21.

Стаття надійшла до редакції 11.04.2018

\section{Кирпичников Ю. А., К.Т.н.;}

Адрощук О. В.;

Петрушен Н. В.;

Васюхно С. И.

Центр военно-стратегических исследований Национального университета обороны Украины имени Ивана Черняховского, Киев

Теоретические подходы к построению архитектуры информационной системы управления оборонными ресурсами на основе сервисно-ориентированной модели

Резюме. Статья посвящена проблеме построения архитектуры информационной системы управления оборонными ресурсами, создание которой сегодня является одной из приоритетных задач оборонной реформы. Децентрализованная архитектура и разрозненность существующих информационных систем в области управления оборонными ресурсами не позволяет получить целостную картину для принятия управленческих решений. Использование архитектуры на основе сервисно-ориентированной модели позволит интегрировать процессы управления в единую информационную систему. С целью определения необходимых изменений в архитектуре предложено теоретико-множественное представление процессов управления оборонными ресурсами и проведена их декомпозиция в виде функциональных моделей “Как есть” и “Как должно быть”. 
Ключевые слова: архитектура информационной системы; сервисно-ориентированная модель; процессы управления оборонными ресурсами.

\section{Y. Kirpichnikov, PhD (Technical);}

O. Androshchuk

N. Petrushen

S. Vasyuhno

Military Strategic Research Center of the National Defence University of Ukraine named after Ivan Cherniakhovskyi, Kyiv

Theoretical approaches to the construction of an information management system for defense resources based on a service-oriented model

Resume. The article is devoted to the problem of building the architecture of the defense resources management information system, the creation of which today is one of the priority tasks of defense reform. Decentralized architecture and disparity of existing information systems in the field of defense resources management does not allow to obtain a coherent picture for making managerial decisions. The use of architecture based on a service-oriented model will integrate management processes into a unified information system. In order to determine the necessary changes in architecture, the set-theoretic representation of the processes of defense resources management has been proposed and their decomposition has been made in the form of functional models "As Is" and "To Be".

Keywords: architecture of the information system; service-oriented model; processes of defense resources management. 